\title{
Andragogical Model in Language Training of Mining Specialists
}

\author{
Evgeniya Bondareva ${ }^{1,}{ }^{*}$, Galina Chistyakova ${ }^{2}$, Yury Kleshevskyi ${ }^{3}$, Sergey Sergeev ${ }^{4}$, and \\ Aleksey Stepanov 5
}

\begin{abstract}
${ }^{1}$ Plekhanov Russian University of Economics, Kemerovo Institute (branch), College of information technologies, economics and law, 650992 Kuznetsky Av. 39, Kemerovo, Russia; Ağrı İbrahim Çeçen University, Department of Russian language and Literature, 04100 Erzurum Road 4 km, Ağrı, Turkey ${ }^{2}$ Plekhanov Russian University of Economics, Kemerovo Institute (branch), Department of Humanities, 650992 Kuznetsky Av. 39, Kemerovo, Russia

${ }^{3}$ Plekhanov Russian University of Economics, Kemerovo Institute (branch), Department of Management and Business technologies, 650992 Kuznetsky Av. 39, Kemerovo, Russia

${ }^{4} \mathrm{Ağr} 1$ İbrahim Çeçen University, Department of Russian language and Literature, 04100 Erzurum Road 4 km, Ağrı, Turkey

${ }^{5}$ Plekhanov Russian University of Economics, Branches Center, 117997 Stremyanny Lane 36, Moscow, Russia
\end{abstract}

\begin{abstract}
Nowadays foreign language competence is one of the main professional skills of mining engineers. Modern competitive conditions require the ability for meeting production challenges in a foreign language from specialists and managers of mining enterprises. This is the reason of high demand on foreign language training/retraining courses. Language training of adult learners fundamentally differs from children and adolescent education. The article describes the features of andragogical learning model. The authors conclude that distance learning is the most productive education form having a number of obvious advantages over traditional (in-class) one. Interactive learning method that involves active engagement of adult trainees appears to be of the greatest interest due to introduction of modern information and communication technologies for distance learning.
\end{abstract}

\section{Introduction}

Modern competitive production conditions require a high level of training, including knowledge of a foreign language, from specialists and managers of mining enterprises for solving many issues at the international level. Adult trainees being professionals in their working area have a critical need for learning a foreign language that is connected with international processes of society liberalization, expansion of international trade and production cooperation, rapid development of new production decisions, effective cooperation with foreign partners in mining sphere.

\footnotetext{
*Corresponding author: bondarevaep@,list.ru
} 
Many centres offering language training and (or) retraining programmes for engineers who actively learn a foreign language as a means of professional communication do not take into consideration some factors that impede quality linguistic education. The fact that an adult needs to be taught in a different way than a child and / or an adolescent has become clear for a long time. The $20^{\text {th }}$ century gave a powerful impulse to the developing of andragogy, a new branch of pedagogy. In the 1970s, American scientists M. Knowles, P. Jarvis, et al suggested the first theoretical theses describing the specific behaviour of adults in learning process. They dwelt upon the procedure model of education as opposed to the content one used in children teaching [1]. Andragogical model involves lifelong learning. In the world practice, the terms adult education, adult learning, adult training, continuing education are used as synonymic expressions.

Research works of many scientists and practitioners are devoted to different aspects of andragogy: general andragogical issues [2, 3, etc.]; organization of courses for adults [4]; methods, technologies and tools used in continuing education $[5,6$, etc.); motivation appeal of adult learners [7, 8, etc.]; training of teaching staff for vocational education [9, etc.]. The issues of language training/retraining of adult learners are discussed in $[10,11,12$, 13, etc.].

Nowadays adult educators should not strive for using as many diverse techniques and technologies as possible. To achieve maximum efficiency, organizers of language courses for adults are to design the learning process by combining the most effective learning methods with capabilities of modern information and communication technologies. Besides, they are to pay special attention to the requirements imposed on their employees by professional communities. In our opinion, it is necessary to offer a clear framework of andragogical learning model, to choose the most effective training methods, and to make practical orientation the cornerstone of adult learning process.

\section{Materials and methods}

There are several reasons for mining professionals to attend language courses. Firstly, to communicate on professional topics effectively one should keep mastering his or her foreign language all the time. If the work process does not involve any tasks that require a foreign language to be completed, linguistic skills become unproductive. Consequently, graduates with Upper-Intermediate or Advanced Level of English cannot communicate fluently as they used to while studying at higher education institutions. Secondly, some mining specialists need to change their specialization area due to some working conditions. So, their aim will be to enlarge vocabulary in some specific professional area. Thirdly, foreign language level of many graduates in Russia leaves much to be desired. Students often have low motivation for studying foreign languages caused by counterproductive combining of learners into training groups (the problem of mixed-abilities groups and the problem of overcrowding groups), the choice of ineffective teaching methods, improper organisation of out-of-class independent work, and failure to use information and communication technologies in the educational process. When former students start working at some enterprises they are often demanded to be able to solve production tasks both in their native and a foreign language. This imperative as well as the desire to get higher salary and to have some career development form steady motivation to improve the foreign language studied before (or even to learn one more). Thus, irrespective of the reason for which learners come to language courses all of them need mastering a foreign language to become professionally and financially stable.

The problem of mixed-abilities groups and the complex of challenges resulted in low motivation are equally essential for language training/retraining courses. The aim of language training centers is quite transparent. They are to make all adult learners successful in solving professional tasks in a foreign language regardless their language level at the be- 
ginning of the course. This article describes one of the ways of designing language training/retraining courses for adult mining specialists.

While choosing a working pattern suitable for trainees / retrainees of language courses one should take into account that they are usually people facing with time and location constraints. To organise traditional in-class lessons with a strict timetable at a definite place is not always possible. Therefore, it is necessary to elect another education form. The best option is believed to be distance learning. The development of distance learning technologies ensures the possibility of providing educational services without being tied to a specific geographical location (Open and Distance Learning). The mixed (distance and in-class) form of education can become a good alternative if the trainees of one course are not too distant-located and are able to meet in class from time to time. This position is supported by the fact that educational results in groups with mixed education forms are the highest as compared to the traditional one [14].

One cannot ignore the fact that modern educational process, organised in distance form, is inconceivable without the use of information and communication technologies (ICT). The supply of educational material through electronic means makes education process fascinating and keeping pace with the times. The reference to the materials of the Internet, the organisation of webinars, the use of interactive multimedia and others are already an indispensable element of learning process. Learners should be provided opportunity to use multiple resources, thus favoring flexibility in the acquisition of knowledge [15].

Modern ICT instruments include MT (machine translation), CAT (computer-assisted translation) and HAMT (human-assisted machine translation) systems aimed to facilitate and speed up translation process. Some MT systems (Yandex translator, Google translator, Translate.ru, etc.) are very popular among learners of all ages. However, in practice, many adult trainees are not aware of the whole sets of capacities provided by the systems used. Similarly, they are not quite skilful in using online and offline dictionaries offering a wide range of opportunities for thematic translation (mining, engineering, geology, etc.). Thus, it is advisable to develop MT, CAT and HAMT skills in the course of training programmes for adult professionals.

Mastering listening and speaking skills is proved to be a highly complicated task for adult learners. The challenge of becoming proficient in these activities is emphasized by many scientific laboratories, including the American Educational Research Association [16]. Consequently, for adult trainees effective foreign language instruction should include less direct teaching and systematic practice involving rules and grammar, and plenty of opportunities for conversation. The educator needs to provide more occasions for communication between trainees themselves. While communicating with each other, adult learners can practice foreign language skills and share their professional experience, discuss some business matters equally important for all of them. This opportunity of professional communication with colleagues throughout the world can become an additional motive for attending language classes. Thus, it is practical professional orientation of language training that must become the cornerstone of continuing language education.

In the context of implementing distance learning technologies and ICT into language training/retraining of mining engineers, the choice of the most effective learning forms and methods is crucial for the process of educational design (specifically targeted planning of training courses). These technologies should encourage adult learners to self-learning alongside with the training programme. Among the innovative methods of foreign language training, the interactive approach appears to be the most promising in terms of distance technologies. It is based on active interaction of learners. Educators act as consultants and coordinators of trainees' educational activities. They step aside while trainees' work intensifies and dominates the process. In combination with ICT, this approach contributes to easier perception of learning and professional information, thus, developing intrinsic moti- 
vation for independent educational activity and demonstrating maximum efficiency in developing professional linguistic competence of adult learners [17]. So, considering professional orientation of language training/retraining courses for mining specialists, the most effective training technology is believed to be interactive learning method.

\section{Results and discussion}

When summarizing authors' long-term teaching practice as well as data from modern scientific and methodological literature, it can be stated that there are some fundamental differences between adult and children education shown in Table 1.

Table 1. Criteria of adult and children education.

\begin{tabular}{|c|c|c|}
\hline Criterion & $\begin{array}{c}\text { Young learner (pedagogical mod- } \\
\text { el) }\end{array}$ & $\begin{array}{l}\text { Adult learner (andragogical mod- } \\
\text { el) }\end{array}$ \\
\hline Aim of learning & Vague, defined by the third party & Clear, defined by the learner \\
\hline Motivation & Often low & High \\
\hline Leading role & Educator & $\begin{array}{l}\text { Learner (wants to study and gain a } \\
\text { skill) }\end{array}$ \\
\hline Independence of learning & Often low & $\begin{array}{l}\text { Often high (wants to manage the } \\
\text { learning process himself) }\end{array}$ \\
\hline $\begin{array}{l}\text { Attitude to learning process } \\
\text { (selected methods, educa- } \\
\text { tional literature, etc.) }\end{array}$ & Often worriless & $\begin{array}{l}\text { Often critical (evaluates the learn- } \\
\text { ing process in terms of his previ- } \\
\text { ous educational experience) }\end{array}$ \\
\hline $\begin{array}{l}\text { Practical orientation of the } \\
\text { skills developed }\end{array}$ & No & Yes \\
\hline Self-discipline & Often low & High \\
\hline $\begin{array}{l}\text { Attitude to timescale of } \\
\text { learning process }\end{array}$ & $\begin{array}{c}\text { Often worriless (ready to learn for } \\
\text { a long time) }\end{array}$ & $\begin{array}{l}\text { Conscious (ready to learn for a } \\
\text { limited time period) }\end{array}$ \\
\hline Content of learning material & Often general & Specific and individual \\
\hline
\end{tabular}

Considering the mentioned characteristics of andragogical educational model, it is expedient to adhere to the principles below, when organising academic work with adults:

- using personal and professional experience of language courses trainees;

- exercising individual approach, flexibility in curriculum development;

- prioritising self-learning;

- practical applying the knowledge acquired and skills developed.

In addition, children learning process and adult learning process differ by the relations "teacher-student". In andragogical model, a teacher is a tutor, a designer of the learning process. His aim is to provide the educational process methodically and only then to act as a source of knowledge (student-centered approach / learner-centered approach). As V. Singh and P. Kharb mention, educators no longer serve chiefly as the dispensers of the subject content, but act as facilitators of learning and evaluators of competency [15]. This essentially different function is often not taken into account by educators of adult training/retraining courses, still exercising teacher-centered approach. 
Thus, when training mining specialists for meeting professional challenges in a foreign language, it is necessary:

- to provide adult learners, non-humanitarian specialists, with the opportunity of quick developing skills for solving production issues in a foreign language with minimum time and finance costs;

- to use modern ICT when designing the learning process,

- to organise a continuous communicative interaction in a foreign language between the trainees.

Further in the article one of possible scenarios of designing language training courses for adult professionals is described. To start with, it is rational to conduct pre-testing of trainees in all language activities (listening, speaking, reading, and writing) to assess their language level. Along with stylistically neutral vocabulary, the tasks should include widely used professional words (e.g. employee, employer, to dismiss, to hire, personnel department, salary, etc.) as well as mining terms (e.g. openings, workings, mine foreman, coalbreaker, etc.). The pre-testing aims to divide trainees into language groups.

The first group is to join trainees with the levels up to Pre-Intermediate. Before the beginning of the main course, such trainees should be offered an intensive language course (not less than 20 hours long) aimed at enlarging active professional vocabulary (stylistically neutral words as well as a minimal set of professional words) and mastering simple grammar constructions necessary for making phrases. The main purpose of the second group of trainees (Intermediate level and upper) at the preparation stage is refreshing their listening and speaking skills (not less than 10 hours long). These trainees will take leading roles in the main course. The work of both groups can be organised in distant and/or mixed forms.

To organise a continuous communicative interaction in a foreign language between the trainees (in combination of the other tasks mentioned above), it is advisable to use interactive learning method. In terms of distance/mixed learning, among interactive teaching techniques the main interest is aroused in: brainstorming, round-table discussion (debate), case study (situational analysis), business game, role play, master classes, etc. This article describes the "Role play" technique as a technology successfully used at language courses for adults, including distant training/retraining language courses for mining specialists.

The "Role play" technique is successfully used in teaching children and adolescents at school, students at colleges and higher educational institutions as well as adults at language training/retraining programmes. There are many kinds of role plays: strategic, educational, organisational, etc. The applicability of the techniques for adult learners is easily explained by the advantages it has. Role plays let to simulate various situations of business interaction; to act in various professional roles; to master foreign language skills in real-like professional situations. The "Role play" technique can also include a number of other technologies involving an active interaction of participants: discussion, brainstorming, manipulative influence, and the search for a manipulation response, etc. In addition, adults are pleased to be included in game-based methods of learning material.

Disadvantages of role plays as a learning technology are reported to include the workload at the preparation stage and the lack of skills in playing a specific role in a real professional interaction. These disadvantages, in our opinion, are fully neutralised in andragogical educational model for two reasons. Firstly, the preparation for the role play is associated with developing foreign language skills that are necessary for real professional and gaming interaction, which corresponds to the main aim of language training/retraining courses. Secondly, adult learners are quite experienced in the professional sphere intended for practicing during the play. So, they can easily perform different professional roles of the area studied.

The basis of the "Role play" technology is an approximate scenario. It is reasonable to discuss some possible variants of scenario as this technology presupposes elements of "free 
speaking" (in contravention of the scenario discussed). The topic for the role play can be offered by the trainees themselves. While practicing foreign language skills they will are able to discuss some real production challenges they encounter with at their enterprises. Thus, the task "practical orientation of adult learning process" can successfully be accomplished.

At the preparation stage the educator is advised to act in different roles: a tutor while giving instructions, a group member while discussing a scenario, an advanced foreign language speaker while working on the wording. The educator can actively help while working with essential vocabulary on the topic (prepare some lexical minimum and some lexical exercises to practice it) and giving parts in the play (as it is he who knows foreign language abilities of all trainees). His main role at this stage is to assist (not to manage).

At the presentation stage the educator's role changes. He cannot assist but only observe the course of the play and caution the participants in case they turn to using their native language. It is necessary to achieve maximum self-regulation of participants. While observing, the educator should record language (speech, grammar, stylistic) and logical mistakes for the following individual and/or group analysis. It is also advisable to record the play to use the video at the evaluation stage.

At the evaluation stage trainees should also play the leading role: they are to be the first who give the language and professional feedback of the play. They are to assess their own language success / failure and that of their group mates. Besides, they can have a kind of round-table discussion on the professional matter discussed during the role play. The role of the educator here is an advanced foreign language speaker who is able to comment on the language and logical mistakes made. He can also offer some after-activity language practice and/or testing.

The core demand of the technique described is speaking the foreign language at all stages of the role play. The only exception can be made for the preparation stage, when vocabulary is being developed. And this is the main duty of the educator to monitor meeting this requirement.

At all stages of the role-playing activity, an extensive use of ICT is expected: online dictionaries and translators when working with vocabulary, video conferences for preparation, presentation and evaluation stages, messengers for the exchange of written documents and visuals, etc.

It is quite obvious that this learning pattern requires from the adult educator to meet the challenge: be competent as a language instructor, and advanced ICT user, an expert in business negotiations, and a specialist in the professional field discussed. So, this is the reason why adult educators should specialise in those professional spheres his or her trainees work at.

\section{Conclusions}

While designing language training/retraining courses for mining specialists, adult educators should follow the principles of andragogical educational model presented below:

- It is necessary to take into consideration the main criteria of adult learning: using trainees' professional experience; exercising individual approach; self-learning; practical applying the knowledge acquired and skills developed; treating the educator as a facilitator of learning and evaluator of language competency.

- Distance (mixed) form of education is the most suitable work pattern in andragogical model. It has a number of advantages of both existential and professional content.

- The extensive use of ICT should become an indispensable element of foreign language learning process. 
- Interactive learning technology is the most productive method of language education for adult trainees.

- Using the "Role play" technique at language courses for mining specialists can meet two challenges: develop foreign language skills and exercise practical orientation of adult training process.

- Other techniques of the interactive learning method can also be effectively used within a framework of andragogical learning model [17].

\section{References}

1. M.S. Knowles, E.F. Holton, R.A. Swanson, The Adult Learner: The Definitive Classic in Adult Education and Human Resource Development (Elsevier Butterworth Heineman, London, New York, 2005)

2. S.B. Merriam, New Directions for Adult \& Continuing Education, 89, 3-14 (2001)

3. E.F. Holton, R.A. Swanson, S.S. Naquin, Perf. Improv. Quart. 14:1, 118-143 (2001)

4. J.K. Dhillon. Stud. Educ. Ad. 48:1, 118-119 (2016)

5. A. Gitterman, J. Teach. Soc. Work, 24:3/4, 95-112 (2004)

6. K. Yang, R. Lawrence, Participatory Visual Approaches to Adult and Continuing Education: Practical Insights (CA: Jossey-Bass, San Francisco, 2017)

7. R.K. Sealana, Examining the Efficacy of Adult Learning of Government-Mandated Content Using Andragogical Delivery Methods versus Traditional Pedagogical Delivery Methods. Doctoral Dissertation (The University of San Francisco, 2014).

8. A. Jenkins, J. Educ. Work, 30:4, 445-455 (2017)

9. K.P. King, P.A. Lawler, New Directions for Adult \& Continuing Education, 98, 5-13 (2003)

10. O. Tarnopolsky, Cog. Educ,, 3, 1135771 (2016)

11. L. Arthur, F. Beaton, Lang. Lear. J., 21:1, 31-36 (2000)

12. M. Lukes, Multil. Res. J. 5:1, 19-38 (2011)

13. T. Deveci, New Horiz. Adult Educ. Hum. Res. Dev.t, 21: 3/4, 16-28 (2017)

14. L.-T. Lee, J. Hung, Hum.-cen. Comp. Inf. Sci. 5, 13 (2015)

15. V. Singh, P. Kharb, J. Anatom. Soc. India, 62:1, 84-89 (2013)

16. R.M. DeKeyser, Am. Educ. Res. Assoc., Res. Poin., 4:1 (2006)

17. G. Chistyakova, E. Bondareva, K. Demidenko, E. Podgornaya, O. Kadnikova, E3S Web Conf. 15, 04010 (2017) 
